since the majority of urinary infections arising outside hospital are caused by strains of Esch. coli of similar biotype, only distinguishable by serological testing.

Advances in clinical medicine have produced new problems for bacteriologists in the interpretation of laboratory results, especially where there is local or general depression of the patient's antimicrobial defence mechanisms. Dr Stokes rightly states that circular arguments between the patient's clinical condition and the bacteriological findings must be avoided. Notwithstanding, to insist on assessing the significance of a growth in blood cultures, from a patient with an artificial heart valve, on laboratory evidence alone may well lead to a dipıheroid or a coagulase negative staphylococcus being discarded incorrectly as a contaminant. Similarly in technical methods, the author does not always show the flexibility of mind and technique demanded by the writer of the preface. For example, she includes a long section on the making and validation of ' 50 droppers' while omitting to mention that it is possible to obtain highly accurate, automatic pipettes with re-sterilizable tips.

However, it would be unfair to allow these small criticisms to detract from what is otherwise a valuable and important book. The high standard of presentation has been maintained in this edition and, at this price, it represents excellent value. To those pathologists, bacteriologists and technicians in training who do not already possess a copy, it is surely an essential work for study and reference, while clinicians will find the non-technical sections on the taking of appropriate specimens, the interpretation of results and hospital infection both lucid and helpful.

\section{Body Fluids in Surgery}

Third edition by A. W. Wilkinson. Pp. $x+307$. Edinburgh and London: E. \& S. Livingstone, 1968. 35s.

The third edition of this book is an important contribution to surgical literature. It gives a lucid account of water and electrolyte balance and its significance in the management of the surgical patient.

Water, sodium, potassium, magnesium and acid base balance are dealt with in the first five chapters. This is followed by two invaluable chapters: the first describes the disturbances in fluid and electrolyte balance that follow intestinal obstruction, fistulae of the gastro-intestinal tract and ureteric transplantation. The second of these two chapters discusses the effect of associated disease, such as liver and renal disease on fluid and electrolyte balance.

There are chapters on shock and plasma substitutes.

The chapter on treatment has been brought up-to-date with the inclusion of the intravenous administration of fat emulsions and amino-acid solutions. Throughout the book, the dangers of intravenous therapy are stressed and the value of early oral feeding or the establishment of a jejunostomy.

The final chapter gives a comprehensive account of fluid and electrolyte balance in infancy and childhood.

The postgraduate student would be wise to study the book in conjunction with a text book of pathology when reading about obstruction, massive resection of the gut etc., but all doctors looking after surgical cases will find sound guidance for dealing with fluid and electrolyte problems.
The Hypochromic Anaemias

By L. J. WitTs. Pp. 126, illustrated. London: William Heinemann Medical Books, 1969. 35s.

The title of this little book is perhaps a bit misleading as the text is almost entirely confined to a discussion of iron deficiency anaemia with only a brief mention of thalassaemia and other sideroblastic anaemias, and the anaemia of infection. The problem of iron deficiency is, however, well and thoroughly covered, but some might take exception to the use of the term idiopathic hypochromic anaemia in these days. Others might feel that only a cursory mention on four separate pages of malabsorption syndromes fails to do justice to this group of disorders as an aetiological factor in chronic hypochromic anaemia.

However, these are relatively minor criticisms of a booklet which gives a good historical and up-to-date account of iron metabolism, the anaemia which results from its deficiency and its treatment. There are many useful references, and the book is well worth reading by those who want more detail than can be obtained from the everyday text books and a generous supply of references for further reading.

\section{Modern Trends in Obstetrics}

Edited by R. J. Kellar. Pp. ix + 370, illustrated. London: Butterworths, 1969. $£ 315 \mathrm{~s}$.

The Modern Trends series have become standard books of reference in postgraduate libraries and the current volume lives up well to its predecessors. There are twelve contributors to the book and the range of subjects is from chromosomal studies in spontaneous abortion to a very interesting chapter on obstetrics in India. It would be unwise to single out particular sections, for all are interesting, but there is a very well written and comprehensive chapter on myometrial contractility from Carl Wood and an excellent section on coagulation defects from Drs Bonnar, McNicol and Douglas. Other excellent sections deal with placental ultrastructure, the foeto-placental unit, cytology, rhesus isoimmunization, hypertension, placental localization and foetal distress.

For the postgraduate in obstetrics and gynaecology, for the doctor coming up to Membership examination of the R.C.O.G. and for the active clinician, there can be no better method of keeping abreast of work in special fields than by reading the books in both obstetrics and gynaecology in the Modern Trends series and we must remain in debt to the contributors for yet another excellent issue.

\section{Obstetrics}

J. M. Holmes. Concise Medical Textbooks. Second edition. Pp. viii +301 , illustrated. London: Bailliere, Tindall \& Cassell, 1969. 28s.

This is the second edition of this text which has appeared in five years and reflects its popularity. One of the series of concise medical textbooks, it does not claim to be in any way an exhaustive volume but provides a concise summary written with authority and sufficient dogma to appeal to the student who must face qualification examination with the facts at his or her fingertips. Anatomy has been omitted from the text and chapters on drug dependence in pregnancy, placental function, placental insufficiency and foetal distress added. Mention is also made of newer diagnostic methods, including foetal scalp sampling, foetal heart monitoring and ultrasonics. It would be difficult to find a book better suited to the needs of the student than this one. 